\title{
Exploring EFL Teachers' and Learners' Perception of L2 Humor: A Case Study of Iranian English Language Institutes
}

\author{
Maryam Farnia a*(i), Shiva Mohammadi b (D) \\ ${ }^{a}$ Department of English Language and Literature, Payame Noor University, PO BOX 19395-3697,Tehran, Iran \\ ${ }^{b}$ Department of Postgraduate Studies, Amin Institute of Higher Education, Taleqani Blv, Fooldshahr, Iran \\ \begin{tabular}{l|l|l} 
Received 20 April 2020 & Received in revised form 20 September 2020 & Accepted 08 March 2021
\end{tabular}
}

APA Citation: Farnia, M., \& Mohammadi, S. (2021). Exploring EFL teachers' and learners' perception of L2 humor: A case study of Iranian English language institutes. Eurasian Journal of Applied Linguistics, 7(1), 151-168.

Doi: 10.32601/ejal.911225

\begin{abstract}
The present paper deals with the perception of Iranian EFL teachers and learners in using humor in language classrooms. To this end, 10 English classes with a population of 70 female and male students and 5 male and female teachers in English language institutes in Esfahan were observed during spring and summer 2019. Using an ethnographic approach, the data were collected through observation and interview. The results showed that both teachers and learners had a positive attitude towards the use of L2 humor in the classroom. Language learners reasoned that having a sense of humor is one of the important qualities a language teacher should possess. The teachers and language learners acknowledged the positive effects of humor such as reducing the distance between teachers and learners, lowering learners' anxiety, boosting learners' retention of the lesson, as well as increasing their concentration and motivation. Moreover, language learners showed a preference for the use L2 humor, course-related humor, and L1 norm-oriented types of humor in their classroom.
\end{abstract}

(C) 2021 EJAL \& the Authors. Published by Eurasian Journal of Applied Linguistics (EJAL). This is an open-access article distributed under the terms and conditions of the Creative Commons Attribution license (CC BY-NC-ND) (http://creativecommons.org/licenses/by-nc-nd/4.0/).

Keywords: Humor perception; appropriate humor; L2 humor; inappropriate humor

\section{Introduction}

Greetings and interacting with friends, laughter, and humor are integral parts of our everyday lives. From a pedagogical vantage point, laughter may be conceived of as the universal language of basic emotion which can help improve health and enhance teaching and learning since instruction is not only concerned with teaching content but also forming and strengthening human connections (Savage, Lujan, Thipparthi, \& DiCarlo, 2017, p. 361). Many research attempts have shown a positive relation between using humor and facilitating the teaching and learning process. These

\footnotetext{
* Corresponding author. Tel.: +98-31-42727121(225)

E-mail address: mfarniair@gmail.com

http://dx.doi.org/10.32601/ejal.911225
} 
studies have shown, inter alia, that the use of humor is beneficial in that it can increase learners' attention, relieve their anxiety, encourage them to take part in class activities, establish a positive class atmosphere, and help them to focus on lessons and recall them more effectively (Powell \& Andresen, 1985).

Studies on the pedagogical implications of humor in foreign language classrooms are abundant (e.g., Bilokcuoglu \& Debreli, 2018; Bolkan, Griffin, \& Goodboy, 2018, to name but a few). However, the observation and investigation of humor across diverse languages and learner cultures and their interaction in the target language and culture can definitely offer valuable insights into understanding humor in world language classrooms (Wagner \& Urios-Aparisi, 2011). In addition, as stated by Baker (2019), "despite the importance of the appropriateness and relevance of humor in educational contexts, very little has been dedicated to understanding what counts as appropriate and relevant humor for the purpose of teaching and learning" (p.137). In the light of what was pointed out above, this study was developed to delve into the use of humor in English language classrooms in an Iranian EFL context. A close observation of humor can not only benefit language learners in strengthening language competence at both communicative and pragmatic level (Hempelmann, 2016), but also assess language learners' mastery of intercultural pragmatics (Ishihara \& Cohen, 2010). As Bell and Pomerantz (2016) state, "humor does have something very important to teach us about how language is used and to contribute to how it is taught and learned in classrooms" (p. 197). To this aim, the investigation is geared towards exploring EFL learners' perception of humor use as well as teachers' use and perception of humor in the classroom. The key variables under study were appropriate/inappropriate humor, relevant/irrelevant humor, and the role and language of humor in EFL classroom

\section{Theoretical Background: Humor in Language Classroom}

To date, several research endeavours have demonstrated the efficacy of using humor in classroom such as enhancing learning speed (Shibinski, \& Martin, 2010), improving the quality of teacher-student relationship (Praag, Stevens, \& Houtte, 2017), improving problem-solving (Klavir \& Gorodetsky, 2001; Shibinski, \& Martin, 2010), relieving stress (White, 2001), improving ratings of teachers' performance (Bryant, Comisky, Crane, \& Zillmann, 1980), reducing test anxiety (Newton \& Dowd, 1990), and increasing perceptions of teacher credibility (Frymier \& Thompson, 1992). Despite this, some teachers refrain from using humor in classroom for reasons such as not being funny or unable to tell a joke, or believing that using humor equals classroom disorder and chaos, or losing class control (Chiasson, 2002; Morrison, 2008). However, in some cases the resistance to use humor stems simply from not knowing how to use it effectively in classroom (Chiasson, 2002).

Several studies have investigated humor production in the classroom (e.g., Shively, 2013); however, a review of the literature reveals that studies on perception of humor are rather scanty and methodologically diverse, and, consequently the reported 
findings are inconsistent (Chen \& Dewaele, 2018). Research into humor in second/foreign language classrooms has investigated, among other issues, the use of humor in relation to the appropriate/inappropriate type of L2 humor (e.g., Bakar, 2019; Wanzer, Frymier, Wojtaszczyk, \& Smith, 2006), teachers' and learners' attitude toward L2 humor use (e.g., Hịşmanoğlu, Ersan, \& Turan, 2018), and relevant/irrelevant types of humor (e.g., Nussbaum, Holladay \& Comadena, 1987). These three issues are discussed below.

With regard to the appropriate/inappropriate type of L2 humor, Lei, Cohen, and Russler (2010) reported that having a sense of humor is an important teacher characteristic which, if used appropriately, could act as an effective pedagogic tool. Wanzer et al. (2006) investigated teachers' and students' perception of appropriate and inappropriate humor in classroom. The results showed four appropriate humor and four inappropriate humor categories. The appropriate categories included related humor (e.g., jokes, stories, teacher performance, teasing), humor unrelated to course material (e.g., college life stereotypes), self-disparaging humor (e.g., making fun of him/herself, making fun of mistakes in the class), and unintentional humor. The inappropriate humor category included disparaging humor targeting 7others (e.g., targeting ethnicity/racial groups, a given sexual orientation), disparaging humor targeting student (e.g., based on gender, intelligence, appearance, religion), offensive humor (e.g., sarcasm, inappropriate jokes), and self-disparaging humor.

In an analysis of teachers' and students' perception of appropriate humor, Baker (2019) reported four types of appropriate humor. To his participants, appropriate humor is relevant, happens at a suitable time and in a suitable manner, and improves teachers' credibility. Baker also found that inappropriate humor is disrespectful humor (p.137). Hellman (2007) suggested that using humor in classrooms makes for a comfortable class atmosphere and sparks learners' interest. Hellman emphasized appropriate and moderate use of humor with regard to audience age, gender, level of language proficiency, and not resorting to offensive and inappropriate humor. Also, Martin, Preiss, Gayle, and Allen (2006) reported positive effects of giving humorous lectures on learning and establishing an enjoyable class atmosphere. Analyzing students' perception of their teachers' use of humor in lecture suggested that they regarded it as a tool used to assist learning, create a more relaxing class environment, and make lectures more interesting.

Relevant to the second issue, teachers and learners' attitude toward L2 humor use, Auerbach (1993) believed that in a context where students do not speak English as an L1, to use "English only in the classroom is neither conclusive nor pedagogically sound" (p.9). Some researchers found a relationship between learners' proficiency level and preference for using L1 or L2 language. In their survey on learners' preference for the use of L1 and L2 humor in classroom, Ayçiçeği-Dinn, Şişman-Bal, and Caldwell-Harris (2017) reported that learners at a low proficiency level perceived jokes in their native language as funnier, while high proficiency learners preferred the use of L2 humor to learn more about different aspects of an L2. Among the number of reasons which are assumed to make jokes sound less funny in a foreign 
language, these researcher mentioned factors such as "comprehension difficulties, altered timing characteristics (because of slower processing in a foreign language) and emotional blunting (reduced emotional resonances in foreign language)" (AyçiçeğiDinn, Şişman-Bal, \& Caldwell-Harris, 2017, p.8).

Touching the third L2 humor use, relevant/irrelevant types of humor, Nussbaum, Holladay, and Comadena (1987) identified two types of humor in classroom: relevant to course content, and not relevant to course content. According to Baker (2019), relevant humor is "related to daily experiences in life; and irrelevant humor is humor that students do not understand" (p.137). Several studies have confirmed that students perceive humor as relevant if it is related to learning content (e.g., Bieg \& Dresel, 2018; Sidelinger, 2014). Deiter's (2000) study of the role of humor in classroom showed that using content-relevant and spontaneous humor had positive effects on learners' attention and promoted learning.

Following the theoretical background, this study was conducted to examine Iranian EFL teachers' and learners' perceptions of L2 humor in classroom in terms of the variables of appropriate/inappropriate humor, relevant/irrelevant humor, and the role and language of humor in classroom.

\section{Method}

To obtain more valid and robust findings, different methods of data collection, i.e., observation and interviews were employed. The details are provided below.

\subsection{Participants}

The data were obtained from 10 classes with 70 English language learners, and 5 language teachers who agreed to participate in the research. The data were collected during spring and summer 2019. The participant teachers included three women and two men with an average age of 25, all holding MA in English language teaching, and Teacher Training Certificate. The teachers had a minimum teaching experience of 3 years. The language learners were 32 males and 38 females with an age range of 16 to 22 who were at lower to upper intermediate levels of language proficiency. It needs to be pointed out that as giving an independent placement was impractical (the reason being failure in getting the institute's consent, as well as learners' unwillingness to participate in a test out of their class schedule), the researchers had to rely on the institute's locally administered language placement test, the proficiency levels students were assigned to, and language learners' self-evaluation report. Gender and language proficiency were not among the variables under investigation.

\subsection{Instruments}

To collect and analyze the data, a concurrent triangulation was employed. The instruments are discussed below.

\subsubsection{Observations}


Following Seaman (2017) and Hempelmann (2016), 7 sessions of 10 English classes held within the span of spring and summer 2019, overall 70 sessions with an average observation rate of 40 minutes, were observed. Due to ethical issues, the researchers were only allowed to voice-record the classes. The researchers adopted an unstructured observation sheet, jotting down any types of humor the teachers used in the classroom. The results of observation sections were used in an interview with teachers and students, too.

\subsubsection{Interviews}

A semi-structured interview was conducted at the end of observation sessions. Each observed class was given a code, and the language learners in each class were interviewed using observation and notes made in their respective classes. The main interview questions attempted to elicit learners and teachers' perception of appropriate/inappropriate humor, relevant/irrelevant humor, and the role and language of humor in classroom. Eleven females and seven males voluntarily participated in the interview. All 5 teachers also agreed to be interviewed.

\subsection{Data Collection Procedures}

We adopted an intensive periods of naturalistic observations for more than six months. Ten classes were observed during spring and summer 2019. As mentioned earlier, 7 sessions of 10 classes were observed for a semester of 16 sessions. To minimize the observer's effect, the researchers decided to ignore the first three sessions, and analyzed the remaining seven sessions of every class. A total of 70 sessions were observed. In doing so, having obtained the respective teachers' and institute's consent, the researchers managed to record the whole class time for 7 sessions. After each session, the collected audios were carefully analyzed to pinpoint humor instances by teachers and language learners. The observers' notes were also analyzed to better understand the type and use of humor in the classroom. Finally, a semi-structured interview in the form of a focus group was conducted at the end of the semester. The focus-group interviews with 2 or 3 volunteer classmates were conducted in each interview session so that more interviews could be carried out and language learners could express their attitude in case of agreement or disagreement with their classmates.

\subsection{Data Analysis}

To analyze the data, observations were coded, making use of tentative codes such as appropriate/inappropriate humor, relevant/irrelevant humor, and the effective/ineffective humor types in the classroom. To ensure the reliability of data interpretation and to minimize the level of subjective judgment, the encoded data sample was reviewed by the second researcher for a consistency check. As the next step, the results were used in the interview session with both teachers and learners. Finally, the results elicited through the two methods were compared and contrasted.

\section{Results}


In this section, the results pertaining to the interviews with teachers and learners and researchers' class observations are reported.

\subsection{The Results of the Observation Sections}

To observe the journal's word limit, the results of analyzing observation sessions of only three out of five teachers are briefly reported in this section. Ten classes were observed for 7 sessions out of 16 sessions of a language course. To this end, an observation sheet and a voice recorder were used.

\subsubsection{The Class of Teacher 1 (T1)}

Teacher 1 had a very friendly and funny class. She was energetic with a great sense of humor. She used different types of humor such as attention grabber via physical intervention, funny memories, cute comments, etc. To illustrate, when a student answered a question incorrectly or did not pay attention to the lesson, she tapped on student's head very gently just as a hint. Students' positively responded to this type of humor as they laughed a lot. Furthermore, they tried to correct their answers or paid closer attention to the class. Also, when the teacher made a mistake herself, e.g., when she mispronounced a word or got her tongue twisted, she hit on her head with a pen and smiled. She corrected herself and allowed students to laugh too.

Sometimes her humor was related to the lesson which was very exciting for students. Once she was teaching a grammar part on the use of must and mustn't. After teaching the structure, she made some funny sentences with students' names explaining what they must or must not do. Students smiled and tried to make some other funny sentences about their friends using this structure. In this way, students learned the grammar structure in a hilarious way.

Examples:

A must not send a message in class when I am teaching.

B must do her homework on time.

C must come to class before the teacher.

This makes for a congenital class atmosphere where students could freely exchange their opinions and ask their questions.

\subsubsection{The Class of Teacher 2 (T2)}

T2 was a serious and strict teacher who used humor mostly when directly related to the content of the lesson. Once she hit on a student's head softly to bring her attention back to the class and although the student smiled, it was completely obvious that she got somewhat demoralized and felt embarrassed among her classmates. T2 often used humor related to the lesson. For example, prior to teaching a reading section, she started telling a funny story related to the topic of reading, and then asked the students to share their funny experiences too. Students showed great interest to contribute to this topic and laughed a lot. As a result, once the teacher wanted to start the reading part, they were so curious to know what the reading was about. 
What was quite conspicuous in this class was the healthy atmosphere where students and teacher interacted; however, it was the teacher who was the sole authority in class and students were not as close to their teacher as those who were in classes of teacher 1 .

\subsubsection{The Class of Teacher 4 (T4)}

T4 was really talkative, energetic with a high sense of humor. He used humor a lot both in break time and during teaching. He actually used all sorts of humor, both relevant and irrelevant to the context of the lesson such as attention grabber via physical intervention, funny stories, and memories, funny comments on students' responses, body gestures and facial expressions. Language learners seemed to be relaxed, were eager to participate in class activity without inhibition and were by no means afraid to give wrong answers or mispronounce a word. However, sometimes the overuse of humor or making humor on certain topics, e.g., politics, seemed to bother the language learners. In such cases, the language learners asked the teacher politely to stop talking off the subject and go back to the lesson. One such example was an occasion when the teacher started to share his opinion on political issues followed by some humorous remarks on one of the political parties in Iran, which sparked further jokes from its opponents and proponents. This act actually split the class over the issue of politics. The teacher did not do anything to control the class because he took it as humor while students were still frantically discussing it. The class atmosphere was really fine and students felt greatly relieved and comfortable; even so, it was obvious that sometimes the students' reaction was a little negative.

\subsection{The Results for Language Learners' Interviews}

In this section, the results vis-a-vis interviews with 18 language learners are presented.

\subsubsection{Language learners' opinion about the use of humor by their teacher in general}

In the first question, the researcher asked language learners to talk about their opinion about their teachers' use of humor in general. All interviewees agreed with the use of humor. On the whole, their answers to this question were related to the usefulness of using humor in the classroom. All 18 students mentioned that the use of humor in classrooms decreases their anxiety and stress by creating a healthy atmosphere between language learners and the teacher and among their classmates.

A male interviewee (aged 16) said that anything changes these days. The new generation's needs are different from the past, stating:

Teachers themselves know that if they do not prepare a funny and an amusing environment, students cannot tolerate the class atmosphere and do not pay attention to the lesson. Students really want to experience an attractive and energetic teaching environment and to have a close relationship with their teacher; so, using humor can be one of the important features of teachers which can help students and teachers to find this connection. 
4.2.2. Students' reactions and feelings towards their teachers' use of humor and its effects on teaching

The second question asked students to talk about their feelings and reactions toward their teacher's use of humor. The participants did not provide any negative response to this question and, on the contrary, said that the use of humor resulted in an atmosphere of camaraderie. Besides, they generally conceded that when they felt more relaxed, they could concentrate on the lesson and express their opinion and more actively take part in class activities which, in turn, facilitated their learning. Participants' responses to this question confirmed the responses in question one in the survey which sought their general opinion of the use of humor in class.

Despite this, the majority of the interviewees agreed that the type of humor which is used by the teacher should be more related to the lesson. One of the female interviewees (aged 21) said:

I really enjoy it when my teacher uses humor in class, but when she uses humor which is not related to lesson, I feel that it is sort of wasting the class time, because most of the time students start to continue that humor and we really get behind the lesson.

However, few respondents considered humor irrelevant to the lesson as wasting the time of the class. Therefore, while the majority responded positively and assumed that the use of humor mostly relevant to the lesson actually facilitates learning, few students, as noticed in the observations, felt inconvenient.

\subsubsection{Students' Opinion of Appropriate and Inappropriate Humor in Classrooms}

The interviewees reported that humor which addressed students' behavior or ethnicity is totally unwelcome. Also, the majority of the interviewees stated that using humor related to nationality, ethnicity, religion, gender and even political issues is inappropriate. They posited that some of these issues are quite personal and people have strong prejudice or belief in them. In effect, they believed, inappropriate use of humor stretches the gap between teachers and language learners.

They pointed out that sometimes an appropriate humor might turn to be inappropriate if it is used in a wrong context. A male student (aged 18) said that:

I am a funny person. I use humor a lot among my friends and they know me very well, but in some situations where my friends are not in a good mood my sense of humor annoys them and they say it. In our class, everyone loves our teacher. He is so energetic and he has a sense of humor. He mostly used appropriate humor such as funny stories and memories, humorous comments, and cute facial expressions and gestures too, but sometimes they were annoying for some other students. Because they were not in a good situation, they got bored, upset or sick. I think the teacher should consider these situations, too.

\subsubsection{Students' Experience of Using Effective Humor by Teacher}


Most language learners had positive experiences of using humor by their teacher. One of the female interviewees (aged 18) and one of the male interviewees (aged 22), who had the same teacher, explained that their teacher uses humor when explaining new words in reading sections. By way of illustration, the teacher used a funny story or anecdotes in Persian to explain the word superstitious, and then explained the same story in English. As a result, they felt so relaxed and became curious to know what the reading is about. One of the effective uses of humor mentioned by some interviewees is when their teacher made a mistake him/herself. One of the interviewees said that:

When our teacher made a mistake while pronouncing a word or even when he tripped on a chair or a table as he was walking in class, he started to laugh and made a joke about himself or corrected himself. In this way, we feel really good and immensely relieved; so, we can express our ideas and take part in class activities without fear of being embarrassed. The teacher showed them it is neither strange nor unusual to make a mistake or anything else, because we all are humans.

In general, the interviewees agreed that a humor is more effective when related to the lesson. They stated that they really liked their teacher and classroom when their teacher used any kinds of humor, but they preferred those instances of humor which were related to the lesson. In this way, not only did the environment of the class change into a more comfortable situation, but also the humor did not act as a distractor.

\subsubsection{Students' Experience of Using Ineffective Humor by Teacher}

In line with the idea of inappropriate types of humor, the majority of the interviewees also believed that the use of humor related to nationality, ethnicity, religion, gender, or political issues is ineffective since this type of humor made the learners uneasy and ashamed. They reported that saying humorous things about learners' outfit, appearance, or accent are truly not effective. However, 5 male interviewees said that the degree of judging these topics as ineffective or inappropriate depends on learners' personality and their relationship with their teacher.

Among other types of ineffective humor is when language learners make a mistake and the teacher uses humor over the mistake. Overuse of humor in a class was another issue the learners regarded as ineffective. They believed that whenever the teacher used too much humor, it could have negative effects. As some of them had experienced, they really felt bored when their teacher overused humor. They believed that the valuable time that should have been allotted to teaching and learning was actually wasted by using that much humor.

\subsubsection{Language Learners' Preference for Using L1 or L2 Humor}

The immediate answer to this question was 'absolutely L2' for the purpose of learning. They said that they learn more vocabulary items in English. One interviewee reported that now that they are in upper levels of language proficiency, 
they prefer to be exposed to more English humor to learn more about the target language and culture. However, in lower level classes, the use of English humor proved a bit puzzling due to their rudimentary familiarity with English culture and language. However, some language learners mentioned, "using L2 humor is always preferable to L1 humor even if we do not fully understand it, because it could be a challenge for us to find new words and sometimes various meanings of each word, which might have a different meaning in humor context; moreover, as learners of English we are supposed to know about different aspects of this language". They actually perceived it as a chance to be get exposure to authentic language use and learn more.

\subsection{Interview with the Teachers}

Some questions were extracted from the results of observations to be asked in a round of interviews with teachers.

\subsubsection{Question \#1: Effects of Humor in Teaching}

In response to the first question "What is your opinion about the effects of using humor during teaching?, all teachers conceded that using humor in classrooms is really important. In fact, they considered it a useful teaching tool. They believed that using humor in classrooms results in a more comfortable atmosphere where language learners' stress is to a great extent relieved.

$\mathrm{T} 1$, T2, and T4 claimed that based on their experiences, using humor always worked as a beneficial and effective tool for teaching. They said that the serious class atmosphere makes learners feel bored and apprehensive. They added that using humor by teachers somewhat bridges the social distance between the teacher and learners, which, they assumed, was common in the educational system in Iran. Three of them stated that oftentimes learners are willing to participate in class activity but the fear of making mistakes hinders their participation. Establishing a comfortable and friendly class environment, by contrast, helps alleviate this feeling. Moreover, they pointed out that using humor relevant to the content of the lesson also helps learners' retention of the content.

The other two teachers (i.e., T3 and T5) added something a little different. Teacher 3 , a female with 3 years of teaching experiences, said:

I agree with the use of humor in class a lot, and I think it really encourages learners to focus on lessons and remember it better. But I think the amount and the type of humor are so important.

Teachers believed that students' reactions to their use of humor were always positive. Teachers claimed that as long as they have experienced during teaching no one showed a negative reaction to their use of humor and no one complained. Although in some situations, learners' reactions to the teachers' use of humor were not completely positive as they showed strange and confusing feedback at first. Once they got to know their teachers better, they showed signs of approving his/her humor. 
T2, who was a female with a four year teaching experience, , explained that she had never received any negative reaction or compliment from students regarding her use of humor in classes, but she admitted that sometimes her use of humor during teaching was out of place in some contexts and she realized it herself.

\subsubsection{Question \#2: Learners' Willingness to Hear Humor in Class}

In response to the second question, "Do the learners want teachers to use humor during teaching? Why or why not?", all the teachers responded Yes. They believed that learners always prefer to experience a funny and friendly atmosphere in the classroom. Furthermore, they wish to learn English in a comfortable and nonthreatening environment where they have a close mutual friendship with their teacher and their classmates. One of the teachers said that:

I remember once I had a problem which made me sad and I was not in a good mood. All my students told me they really loved me more when I was funny and used humor.

\subsubsection{Question \#3: Humor in English or Persian}

In response to the third question, "Do you prefer English or Persian humor?", the teachers said both. They stated that their preference for English or Persian humor well depended on a number of factors including learners' proficiency level, age, and the topic.

They added that whenever they use Persian humor and in Persian, students generally understand better and take it more efficiently as it makes learning fun. When they used English humor in English, they try to make sense of it and learn more about English culture, too. When they used Persian humor but in English students can learn some new English words or structures.

\subsubsection{Question\#4: Inappropriate Humor?}

In response to the fourth interview question, "What is your opinion of inappropriate humor in class?", all interviewees believed that making jokes on learners' outfit and appearance is an inappropriate type of humor because this seems to be a sensitive issue to learners. Other inappropriate types of humor, according to the teachers, are humor related to ethnicity and gender. On the other hand, some of them stated that using attention grabber via physical intervention is not appropriate because students feel embarrassed in presence of their fellow classmates. T4 who was a male with a four year teaching experience believed that humor is just humor and for fun only.

He said:

If you made a close relationship with your students and they accept you as one of their friends, they do not become sad or feel uncomfortable when you use any types of humor. His view about using humor related to students' appearance and behavior was different too.

He mentioned that when a teacher tries to act like a close friend of students, they accept the humor and do not feel embarrassed. In this study from among all interviewed teachers whose classes were observed in some sections the majority 
argued for the use of humor in classes and showed great interest in using it in their classes. Generally, the beneficial effects of humor mentioned by teachers were more than its probable detrimental effects in classes. Teachers' perception of using humor in classes during the teaching and learning process was in line with the direct and indirect benefits of using humor explained in the literature review above.

\section{Discussion}

In response to the first research question which addressed Iranian EFL teachers' perceptions of L2 humor, the interview results showed that all teachers used humor in their classes, even those who are not often recognized as a funny teacher, a finding which was consistent with the researchers' observation report. Overall, teachers agreed that the use of humor can facilitate teaching by easing learners' tension while learning or using an L2. They added that the use of humor can turn the class atmosphere into a more active and comfortable environment, substantially reduce learners' anxiety, and bridge the distance between teacher and students. This chimes with studies which lent support to the positive effects of using humor on improving the quality of teacher-student interaction (Praag, et al., 2017), relieving language learners' stress (White, 2001), and enhancing the efficacy of language teaching (Kehr,Molstad, \& Donahue, 1999). Teachers reported that building humor into teaching not only helped learners to comprehend and grasp the lessons more efficiently, as Lucas (2005) claimed, but also enabled them to remember and recall the lessons better, a result which upholds Garner (2006) and Kaplan and Pascoe's (1977) research findings.

The results of analyzing teachers' interviews revealed that resorting to humor is capable of improving the quality of teacher and learner relationship and easing learners' stress and test anxiety as well as encouraging learners to express themselves freely and take part in class activity eagerly. This is in keeping with Goodboy, Booth-Butterfield, Bolkan and Griffin's (2015) findings indicating that the use of humor can exert a significant beneficial effect on students' learning, class participation, extra effort, and relation with their teacher in and out of the classrooms. Similarly, Powers's (2008) findings showed that using humor is a tool in teaching that could help teachers to establish an intimate connection with students, alleviate their stress, and manage the class better.

Teachers' reports also suggested that language learners welcome the use of humor in the class which in turn encourages the teachers to incorporate more humor into their teaching in the classroom. This replicated previous studies (e.g., Bryant et al., 1980; Powell \& Andresen, 1985) which reported that from the students' point of view, teachers' use of humor is one of the most influential factors contributing to the quality of the educational system. As observed in interviews with the learners, the use of inappropriate humor might have unfavourable effects on the class atmosphere. It is argued that an appropriate humor conforms to the learners' expectations and norms of the class (Spitzberg \& Cupach, 1984). The inappropriate humor, on the other hand, 
is against learners' norms (Levine et al., 2000). According to Steele (1998), both learners and teachers believed that inappropriate humor could have negative effects on the class. To them, using any type of humor based on learners' outfit and appearance, politics, and ethnicity is inappropriate and should be avoided. This is in line with Wanzer et al.'s (2006) study where participants reported that making fun of students' appearance, outfit, religion, etc. is a clear example for inappropriate humor. Viewed from the language learners' perspective, the overuse of humor in language classroom somewhat wastes the class time, and does not lead to desirable results, an observation which replicated Benjelloun's (2009) findings.

In response to the second objective that concerned Iranian EFL learners' perceptions of L2 humor, results of learners' interviews clinched the positive role of using humor. Learners mentioned that using humor in class environment leads to creating a more relaxing and comfortable class environment, encouraging students to assume a more active role in class activities and streamlining their learning and retention process. Learners' views supported Martin et al., (2006), and Hellman's (2007) studies which mentioned that using humor in class environment prepares a comfortable and friendly atmosphere thereby galvanizing learners' interest. This is also accordance with Powell and Andresen's (1985) study which showed that using humor in classes not only creates a more comfortable atmosphere, but also captures learners' attention, decreases their anxiety, and prompts them to take part in class activities. Learners considered having a sense of humor as an essential quality a good teacher must possess. This finding confirmed Lei, Cohen, and Russler (2010) who also observed that students perceived having a sense of humor as an important teacher characteristic.

According to Cook (2000), learning a language is not just learning the rules and doing the exercises but how to interact and communicate in the language. Results of learners' interviews demonstrated that they prefer to have more interaction in a class where humor is built into activities. The appropriate humor, according to them, lets them enjoy the class and helps them handle conversations with less anxiety.

Results of interview and observation analyses showed that teachers sometimes use L1 Persian to tell a joke, give a funny feedback/story with the purpose of helping learners understand the lesson. The teachers reported that when making a choice between using L1 or L2 humor, they take into consideration learners' proficiency level and the topic of the lesson. The results of teachers' interview and the learners' survey analyses were in line with Schweers (1999) and Tang (2002) who highlighted the importance of using L1 as a supportive and facilitative strategy to provide a sense of security in foreign language classrooms. According to Auerbach (1993, p. 19), "Starting with the L1 provides a sense of security and validates the learners' lived experiences, allowing them to express themselves. The learner is then willing to experiment and take risks with English". In their experiment, Ayçiçeği-Dinn, ŞişmanBal, and Caldwell-Harris (2017) considered learner's proficiency level when using L1 or L2 humor. The findings of this research are in line with those previously reported by Ayçiçeği-Dinn, Şişman-Bal, and Caldwell-Harris (2017) suggesting that learners 
at high proficiency levels preferred to learn more about different aspects of the second language through humor. A reverse tendency was observed among learners with a lower level of proficiency.

Humor orientation or a predisposition to be funny (Booth-Butterfield \& BoothButterfield, 1991) is the ability to create humorous messages. Often, more types of humor such as relevant/irrelevant, appropriate/inappropriate, self- or otherdisparaging are found in classes with teachers who have a high- humor orientation (Wanzer, Frymier \& Irwin, 2010). In other words, there is a positive correlation between teachers' humor orientation and the number of inappropriate humor they use (Frymier, Wanzer, \&Wojtaszczyk., 2008). The findings of the observations revealed that teachers who conceived of themselves as being funny or had a high humor orientation used different types of humor including those which learners might deem inappropriate.

Generally speaking, the findings showed that using humor in classes helped set up a more comfortable atmosphere where the distance between teacher and learners was reduced and learners' motivation was enhanced.The majority of learners agreed that the use of humor in foreign language learning is important as it positively impacts their motivation and concentration. A healthy classroom environment is pivotal to effective learning and focused attention because it removes learners' psychological barriers. It also arouses learners' interest and acts as a facilitative factor significantly promoting their learning. Using humor in classes not only has beneficial effects on learners' learning but also improves their' performance and helps them remember and retain the materials they learnt.

\section{Conclusion}

The present research examined English language teachers' and learners' perception of humor in English language classroom. All in all, the results spoke to both teachers' and learners' positive attitude towards the use of humor in L2 classes. The findings of this study have pedagogical implications for foreign language teaching classes. The results reveal that the use of humor in class is considered effective and beneficial, and has both direct and indirect contributions to language classroom such as easing students' anxiety, bridging the distance between teacher and learners, and creating a comfortable atmosphere for language learners. Nevertheless, the teachers should be cognizant of the type and frequency of use of humor they use so as to avoid inappropriate or overuse of humor in the classroom.

This research has some limitations which should be acknowledged. First, for reasons of availability and practicality, the researchers managed to observe only one English institute. Second, gender and learners' age were not taken into consideration as independent variables. Hence, examining female and male students' perception of humor, the effects of teacher's gender on students' perception of his/her use of humor, and even the probable differences regarding female and male learners' perception of humor, coeducational or segregated classes, or even variation in humor perception 
due to age differences could be avenues for future research. Moreover, because it was impractical to administer a placement test, the language proficiency criteria were limited to students' self-reports and the classes they were assigned to at the institute. Thus, future studies are also needed to explore the potential linkage between variation in language proficiency and learners' perception of humor.

\section{The Research and Publication Ethics Statement}

The Ethics Committee/Board approval for this study was obtained from Amin Institute of Higher Education Ethical Board in 02/19/2019 by No 2535440. No ethical considerations were violated in this study.

\section{The Conflict of Interest Statement}

In line with the statement of Committee on Publication Ethics (COPE), we hereby declare that we had no conflicting interests regarding any parties of this study.

\section{References}

Auerbach, E. (1993).Re-examining English only in the ESL classroom. TESOL Quarterly, 27(1), 9-32.

Ayçiçeği-Dinn, A., Şişman-Bal, S. \& Caldwell-Harris, C. (2017). Are jokes funnier in one's native language? Humor: International Journal of Humor Research,31(1). 5-37, https://doi.org/10.1515/humor-2017-0112.

Baker, F. (2019).Appropriate and relevant humor in the university classroom: insights from teachers and students. European Journal of Humor Research, 7(4), 137-152. http://dx.doi.org/10.7592/EJHR2019.7.4.bakar

Benjelloun, H. (2009). An empirical investigation of the use of humor in university classrooms. Education, Business and Society: Contemporary Middle Eastern Issues, 2(4), 312-322. doi:10.1108/17537980911001134

Bieg, S. \&Dresel, M. (2018). Relevance of perceived teacher humor types for instructions and student learning. Social Psychology of Education, 21(4), 805-825. https://doi.org/10.1007/s11218-018-9428-z

Bilokcuoglu, H., \& Debreli, E. (2018). Use of humor in language classes: an effective 'filter' or affective filter? Journal of Language and Linguistic Studies, 14(3), 347-359. https://files.eric.ed.gov/fulltext/EJ1193190.pdf

Bolkan, S., Griffin, D. J. \& Goodboy, A. K. (2018). Humor in the classroom: the effects of integrated humor on student learning, Communication Education, 67(2), 144-164. doi: 10.1080/03634523.2017.1413199.

Booth-Butterfield, M., \& Booth-Butterfield, S. (1991). Individual differences in the communication of humorous messages. Southern Communication Journal, 56, 32-40. https://doi.org/10.1080/10417949109372831

Bryant, J., Comisky, P.W., Crane, J. S., \& Zillmann, D. (1980).Relationship between college teachers' use of humor in the classroom and students' evaluations of their teachers. Journal of Educational Psychology, 72, 511-519. https://doi.org/10.1037/0022-0663.72.4.511

Chen, X., \& Dewaele, J. M. (2018).The relationship between English proficiency and humor appreciation among English L1 users and Chinese L2 users of English. Applied Linguistics Review.10(4),653-676. https://doi.org/10.1515/applirev-2018-0002 
Chiasson, P. E. (2002). Using humor in second language learning. The Internet TESL Journal, 3(3). Retrieved from http://iteslj.org/Techniques/Chiasson- Humour.html.

Cook, M. (2000). Writing and role play: A case for inclusion. Literacy, 34(2), 47-78. https://doi.org/10.1111/1467-9345.00138

Deiter, R. (2000). The use of humor as a teaching tool in the college classroom. NACTA Journal, 44 , 20-28. https://pdfs.semanticscholar.org/e22f/8d3d510011d5ad57274b15dbd2fc9617c239.pdf

Frymier, A.B., \& Thompson, C.A. (1992).Perceived teacher affinity-seeking in relation to perceived teacher credibility. Communication Education, 41(4),388-399. https://doi.org/10.1080/03634529209378900

Frymier, A. B., Wanzer, M. B., \&Wojtaszczyk, A. M. (2008). Assessing students' perceptions of inappropriate and appropriate instructor humor. Communication Education, 57, 266-288. https://doi.org/10.1080/03634520701687183

Garner, R. L. (2006). Humor in pedagogy: How Ha-Ha can lead to Aha! College Teaching, 54(1), 177-180.https://doi.org/10.3200/CTCH.54.1.177-180

Goodboy, A.K., Booth-Butterfield, M., Bolkan, S., \& Griffin, D. J. (2015). The role of Instructor humor and students' educational orientations in student learning, extra effort, participation, and out-of-class communication, Communication Quarterly, 63(1), 44-61, https://doi.org/10.1080/01463373.2014.965840

Hellman, S. (2007). Humor in the classroom: Stu's seven simple steps to success. College teaching, 55, 37-39. https://doi.org/10.3200/CTCH.55.1.37-39

Hempelmann, C. (2016). Humor in the teaching of writing: A microethnographic approach. EuroAmerican Journal of Applied Linguistics and Languages, 3(2), 42-55, http://dx.doi.org/10.21283/2376905X.5.72

Hịşmanoğlu, M., Ersan, Y., \& Turan, Y. Z. (2018). Turkish EFL learners' perceptions on teachers' using humor in the EFL classroom. International Journal of Languages' Education and Teaching. 6(2), 284-294. https://www.researchgate.net/publication/326062780_Turkish_EFL_Learners'_Perceptions on_Teachers'_Using_Humor_in_the_EFL_Classroom

Isihara, N., \& Cohen, A. D. (2010). Teaching and learning pragmatics: Where language and culture meet. London and New York: Routledge.

Kaplan, R. M., \& Pascoe, G. C. (1977). Humorous lectures and humorous examples: Some effects upon comprehension and retention. Journal of Educational Psychology, 69, 61-65, https://doi.org/10.1037/0022-0663.69.1.61

Kehr, N. M., Molstad, S., \& Donahue, R. (1999). Using humor in the college classroom to enhance teaching effectiveness in 'dread courses'. College Student Journal, 33(3): 400-406. https://jan.ucc.nau.edu/ slm/AdjCI/Startclass/Humor.html

Klavir, R., \&Gorodetsky, M. (2001).The processing of analogous problems in the verbal and visual-humorous (cartoons) modalities by gifted/average children. Gifted Children Quarterly,45(3), 205-215. https://doi.org/10.1177/001698620104500305

Lei, S.A., Cohen, J. L., \&Russler, K. M. (2010).Humor on learning in the college classroom: Evaluating benefits and drawbacks from instructors' perspectives. Journal of Instructional Psychology, 37, 326-331. https://scinapse.io/papers/153638748

Levine, T. R., Anders, L. N, Banas, J., Baum, K. L., Endo, K., Hu, A. D. S., \& Wong, N. C. H. (2000). Norms, expectations, and deception: A norm violation model of veracity judgments. Communication Monographs, 67(2), 123-137. https://doi.org/10.1080/03637750009376500

Lucas, T. (2005). Language awareness and comprehension through puns among ESL learners. Language Awareness, 14(4), 221-238. https://doi.org/10.1080/09658410508668838 
Martin, D. M., Preiss, R. W., Gayle, B. M., \& Allen, M. (2006).A Meta-Analytic Assessment of the Effect of Humorous Lectures on Learning. In B. M. Gayle, R. W. Preiss, N. Burrell, \& M. Allen (Eds.), Classroom communication and instructional processes: Advances through meta-analysis (p. 295-313). Lawrence Erlbaum Associates Publishers.

Morrison, M. K. (2008). Using humor to maximize learning: The links between positive emotions and education. Maryland: Rowman \& Littlefield Education.

Newton, G. R., \& Dowd, E. T.(1990). Effect of client sense of humor and paradoxical intervention on test anxiety. Counseling \& Development, 68(6), 668-672, https://doi.org/10.1002/j.1556-6676.1990.tb01434.x

Nussbaum, J. F., Holladay, S. J., \& Comadena, M. E. (1987).Classroom verbal behavior of highly effective teachers. Journal of Thought, 22(4), 73-80. https://www.jstor.org/stable/42589249? seq=1

Powell, J. P., \& Andresen. L. W. (1985). Humour and teaching in higher education. Studies in Higher Education, 10, 79-90. https://doi.org/10.1080/03075078512331378726

Powers, T. (2008).Engaging students with humor. In B. Perlman, L. I. McCann, \& S. H. McFadden (Eds.), Lessons learned: Practical advice for the teaching of psychology (pp. 5362). Washington, DC: Association for Psychological Science.

Praag, L.V., Stevens, P.A.J., \&Houtte, M.V. (2017). How humor makes or breaks studentteacher relationships: A classroom ethnography in Belgium. Teaching and Teacher Education, 66, 393-401. https://biblio.ugent.be/publication/8521682

Savage BM, Lujan HL, Thipparthi RR, \& DiCarlo SE (2017) Humor, laughter, learning, and health! A brief review. Advances in Physiological Education, 41, 341-347. https://doi.org/10.1152/advan.00030.2017

Schweers, C. (1999) Using L1 in the L2 classroom. English Teaching Forum, 37, 6-13.

Seaman, L. G. (2017).Exploring student engagement and middle-school students' perceptions of humor used as a teaching tool. PhD dissertation. Northcentral University, The United States.

Shibinski, K. \& Martin, M. (2010).The role of humor in enhancing the classroom climate. Human Kinetics Journals, 27-29. https://journals.sagepub.com/doi/abs/10.1177/1045159515596160

Shively, R. L. (2013). Learning to be funny in Spanish during study abroad: L2 humor development. The Modern Language Journal, 97(4), 930-946. https://doi.org/10.1111/j.1540-4781.2013.12043.x

Sidelinger, R. J. (2014). Using relevant humor to moderate inappropriate conversations: Maintaining student communication satisfaction in the classroom. Communication Research Reports, 31 (3), 292-301. https://doi.org/10.1080/08824096.2014.924339

Spitzberg, B. H., \&Cupach, W. R. (1984). Interpersonal communication competence. Newbury Park, CA: Sage.

Steele, K. E. (1998). The positive and negative effects of the use of humor in the classroom setting. Unpublished master's dissertation, Salem-Teikyo University.

Tang, J. (2002). Using L1 in the English classroom. English Teaching Forum, 40(1), 36-43. https://americanenglish.state.gov/files/ae/resource files/02-40-1-h.pdf

Wagner, M., \&Urios-Aparisi, E. (2011). The use of humor in the foreign language classroom: Funny and effective? International Journal of Humor Research, 24(4), 399-434. doi.10.1515/HUMR.2011.024

Wanzer, M. B., Frymier, A. B., Wojtaszczyk, A. M., \& Smith, T. (2006). Appropriate and inappropriate uses of humor by teachers. Communication Education, 55, 178-196. https://doi.org/10.1080/03634520600566132 
Wanzer, M. B., Frymier, A. B., \& Irwin, J. (2010). An explanation of the relationship between instructor humor and student learning: Instructional humor processing theory. Communication Education, 18 59(1), https://doi.org/10.1080/03634520903367238

White, G. W. (2001). Teacher's report of how they used humor with students perceived use of such humor. Education, 122 (2), 337- 347

\section{Copyrights}

Copyright for this article is retained by the author(s), with first publication rights granted to the Journal.

This is an open-access article distributed under the terms and conditions of the Creative Commons Attribution license (CC BY-NC-ND) (http://creativecommons.org/licenses/by-nc-nd/4.0/). 